\title{
Moya Moya disease presenting as Chorea: A case report
}

\author{
Quraishi SMS ${ }^{1}$, Hussain KMI², G Rajni ${ }^{3}$, Afzal $S^{4}$
}

${ }^{1}$ Dr S M Saifullah Quraishi, Assistant professor, Kurnool Medical college Kurnool, ${ }^{2}$ Dr K M Iqbal Hussain, Assosiate Professor, Kurnool medical college Kurnool, ${ }^{3}$ Dr G Rajini, Post graduate Student, Department of Medicine, Kurnool Medical college Kurnool, ${ }^{4}$ Dr Sayeeda Afzal , Post graduate student in Paediatric, GVR children hospital Kurnool, India

Address for correspondence: Dr S M Saifullah Quraishi, Email-safu53@yahoo.co.in

\begin{abstract}
Moya Moya disease is traditionally known as disease of adults. Name is derived from angiographic appearance of cerebral vessels. Here we are reporting a case of Moya Moya disease in a young adolescent girl.
\end{abstract}

Key words: Moya Moya disease, chorea, involuntary movement.

\section{Introduction}

Moya moya disease is a rare disease characterized by multiple occlusions of the cerebral circulation with an unusual net like system of collaterals. In Japanese moya moya means HAZY. The disease derives its peculiar name from the angiographic appearance of cerebral vessels in the disease that resembles a 'PUFF OF SMOKE'. Ischemic insult is more common in children. Chorea is rarely noted with this disease. When a child presents with chorea, clinicians may attribute this symptom to a number of diseases. Any child with involuntary movements, moya moya disease can be a possibility.

\section{Case report}

A 13 year old girl with history of sudden onset of right hemiparesis at the age of 3 years, recovered in 4 hours, later at the age of 8 years she developed involuntary movements of right upper limb and lower limb which subsided spontaneously, thereafter she is having on and off rhythmic, transient, dance like movements involving right upper and lower limbs with no loss of consciousness.

On examination, her consciousness was clear with good orientation. A detailed physical examination showed that the functions of cranial nerves were normal. No residual weakness of right upper and lower limbs. Hypotonia of right upper and lower limb present. Deep tendon reflexes were normal. No pathological reflexes. sensory system was intact. Frequent episodes of chorea involving right upper and lower limb were observed.
Laboratory tests including a complete blood count and tests for anti streptolysin o titer, rheumatoid factor, anti nuclear antibodies, anticardiolipin antibodies, anti ds DNA, lipid profile, ESR, CRP, homocysteine, $\mathrm{Hb}$ electrophoresis, 2D Echo were unremarkable. CT scan brain at the time of hemiparesis showing small infarct left superior frontal region. Later when child presented with involuntary movements, MR angiography revealed diffuse narrowing of left internal carotid artery with critical stenosis of supraclinoid segment, paucity of left middle cerebral artery branches, non visualization of A2 segment of right anterior cerebral artery, narrowing of A1 segment of left anterior cerebral artery at origin. Digital subtraction angiography shows complete occlusion of left distal internal carotid artery and its branches beyond supraclinoid segment, prominent collaterals seen at the level of basifrontal lobes. Hypertrophied dural collaterals are seen arising from the ophthalmic artery suggestive of moya moya disease [figure1 ]. Patient is on medical management receiving aspirin and valproate. Episode of chorea has decreased with medicine.

\section{Discussion}

In children, moya moya disease presents with symptoms suggestive of ischemia of brain. These include headache, seizures, focal neurological deficit, recurrent TIA [1]. Headache is a common presentation due to dilatation of leptomaningial and dural collateral vessel stimulating dural nociceptor [2]. Involuntary movements [chorea] have been rarely described previously [3]. 


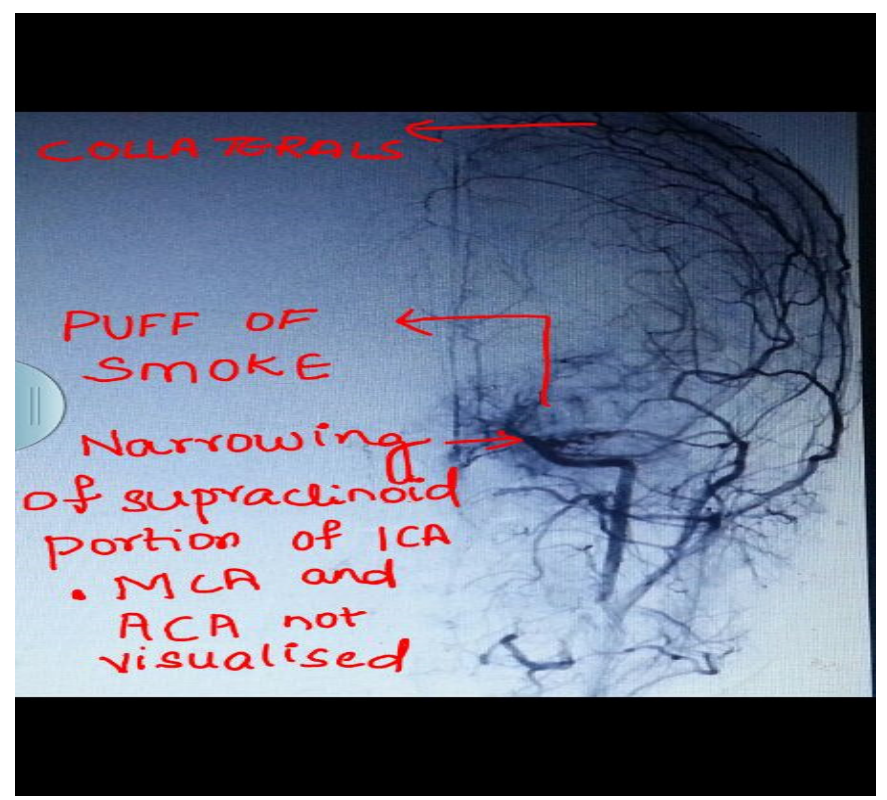

Fig 1: Puff of Smoke appearance suggesting Moya Moya disease

Chorea in moya moya disease may be an early warning sign of vascular insufficiency in the brain. In children with crying and breath holding episodes can precipitate abnormal movements due to decrease blood supply in critical area [4]. There are reports of association of moya moya disease with Variety of disorder like radiotherapy of head and neck, sickle cell anemia, Neurofibromatosis type 1, autoimmune disorder [Grave disease, Antiphospholipid syndrome] and congenital heart disease, but most common is idiopathic [5]. In this patient no association with other disease was found.

Vascular bypass are performed to increase perfusion and to decrease hypoxia in brain. Clinical and angiographic improvement can be seen after bypass procedure in all age group patients unless patient had permanent neurological damage in the form of infarct [6]. As the course of disease is unpredictable sometimes it is slowly progressive with intermittent neurological event or occasionally disease can have fulminant course. However clinical symptoms invariably progress irrespective of angiography finding in untreated patient [7]. Medical therapy cannot halt progression of disease [8]. Surgical treatment delays symptomatic neurological progression, that is why timing of surgery is very important. Even in presence of severe angiographic changes if revascularization surgery is done before disabling infarct, prognosis is excellent [9]. Delay in diagnosis results in delay in treatment and increasing permanent disability from stroke. Medical therapies mainly confined to treat acute episode like seizure and infarct.

\section{Conclusion}

In children and young adult presenting with stroke we should consider moya moya disease. Early revascularization surgery will prevent permanent neurological disability.

Most important predictor of overall outcome in moya moya is neurological status at the time of treatment.

\section{Reference}

1. Han DH, Kwon OK, Byun BJ, Choi BY, Choi CW, Choi JU, Choi SG, Doh JO, Han JW, Jung S, Kang SD, Kim DJ, Kim HI, Kim HD, Kim MC, Kim SC, Kim SC, Kim Y, Kwun BD, Lee BG, Lim YJ, Moon JG, Park HS, Shin MS, Song JH, Suk JS, Yim MB, A cooperative study: clinical characteristics of 334 Korean patients with moyamoya disease treated at neurosurgical institutes (1976-1994). The Korean Society for Cerebrovascular Disease. Acta Neurochir (Wien) 2000;142(11):1263-73.

2. Seol HJ, Wang KC, Kim SK, Hwang YS, Kim KJ, Cho BK. Headache in pediatric moyamoya disease: review of 204 consecutive cases. J Neurosurg 2005;103(Suppl 5):439-42

3. Watanabe K, Negoro T, Maehara M, Takahashi I, Nomura K, Miura K. Moyamoya disease presenting with chorea. Pediatr Neurol. 1990 Jan- Feb;6(1):40-2 
4. Hany SH, Kim YG, Cha SH, Chung SY. moyamoya disease presenting with signing induced chorea. J Neurol Neurosurg Psychiatry 2000;69;6 833-834

5. Lutterman, J., Scott, M., Nass, R., Geva, T. "Moyamoya syndrome associated with congenital heart disease," Pediatrics, vol. 101, no. 1, January 1998, Pages 57-60.

6. Choi JU, Kim DS, Kim EY, Lee KC: Natural history of moyamoya disease: comparison of activity of daily living in surgery and non surgery groups. Clin Neurol Neurosurg 1997;99(Supp1 2):S11-18.

7. Scott RM, Smith JL, Robertson RL, Madsen JR, Soriano SG, Rockoff MA. Long-term outcome in children with moyamoya syndrome after cranial revascularization by pial synangiosis. J Neurosurg2004;100(2 Suppl Pediatrics):142-9.

8. Kuroda S, Ishikawa T, Houkin K, Nanba R, Hokari $\mathrm{M}$, Iwasaki Y. Incidence and clinical features of disease progression in adult moyamoya disease Stroke 2005;36(10):2148-53.

9. Fukuyama Y, Umezu R. Clinical and cerebral angiographic evolutions of idiopathic progressive occlusive disease of the circle of Willis ("moyamoya"'disease) in children. Brain Dev 1985;7(1):21-37.

\section{How to cite this article?}

Quraishi SMS, Hussain KMI, G Rajni, Afzal S. Moya Moya disease presenting as Chorea: A case report. Int J Med Res Rev 2014;2(3):256- 258. doi:10.17511/ijmrr. 2014.i03.15. 